\title{
РОССИЯ НА МЕЖДУНАРОДНОМ РЫНКЕ ТЕХНОЛОГИЙ
}

\section{RUSSIA ON THE INTERNATIONAL TECHNOLOGY MARKET}

T. Ason

A. Mutallapova

Summary. The article analyzes the position of Russia on the international technology market, identifies the country's main problems in this segment of the international market, and identifies its prospects. The author revealed that currently the two most powerful players in the international technology market are the United States and China, which are holding a large share of the market in their hands. Russia, in turn, should pay attention to various forms of cooperation and cooperation with foreign research centers and organizations, in particular on the joint creation of technology companies - future leaders of the international technology market.

Keywords: technologies, Russia, international market, research and development, international trade, innovations, scientific and technical activities..

\author{
Асон Татьяна Анатольевна \\ К.э.н., дочент, Финансовый университет при \\ Правительстве РФ (г. Москва) \\ tatiana_ason@mail.ru \\ Муталлапова Альбина Артуровна \\ Финансовый университет при Правительстве РФ \\ (2. Москва) \\ albinka0299@yandex.ru
}

Аннотация. В статье проанализировано положение России на международном рынке технологий, определены основные проблемы страны в данном сегменте международного рынка, а также обозначены ее перспективы. Автором выявлено, что в настоящее время на международном рынке технологий два самых сильных игрока — США и КНР, которые сосредотачивают в своих руках большую долю рынка. России в свою очередь стоит уделять внимание различным формам сотрудничества и кооперации с зарубежными исследовательскими центрами и организациями, в особенности по совместному созданию технологических компаний - будущих лидеров международного рынка технологий.

Ключевые слова: технологии, Россия, международный рынок, научно-исследовательские разработки, международная торговля, инновации, научно-техническая деятельность.

миллиона долларов США, что в 7 раз выше показателей 2001 года (636,9 миллионов долларов). В процентном выражении внешнеторговый оборот в 2018 году сократился на $0,36 \%$.

Также с 2017 по 2018 год уменьшились выплаты по импорту технологий на 7,28\% и на $19 \%$ увеличились поступления от экспорта, немного сократив разницу между экспортом и импортом: с 2124 миллионов долларов США в 2017 году до 1 659,2 миллионов долларов США в 2018 году.

Рассматривая структурную часть технологического экспорта и импорта России, можно отметить, что как в 2018 году, так и в 2017, большую часть экспорта и импорта составили инжиниринговые услуги - 51,4 и 45,9\% соответственно.

Удельный вес денежных поступлений от экспорта по соглашениям, предметами которых являлись охраняемые объекты промышленной собственности, составил лишь 2,4\%, в то время как в структуре выплат по импорту их доля достигала на $35,2 \%$.

На рисунке 2 показана общая доля поступлений по патентам на изобретения, селекционные достижения, 


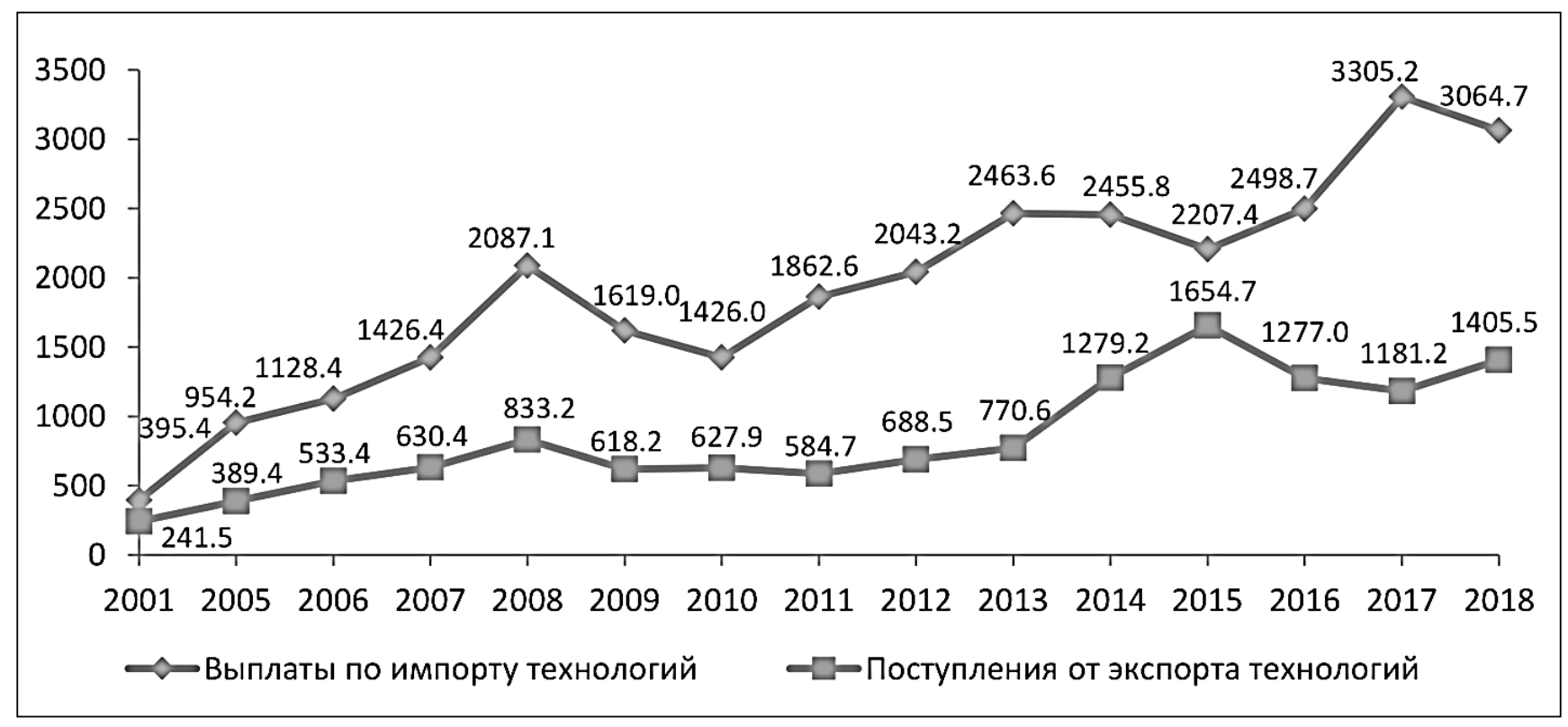

Рис. 1. Динамика экспорта и импорта технологий России (в млн. долл. США) [3].

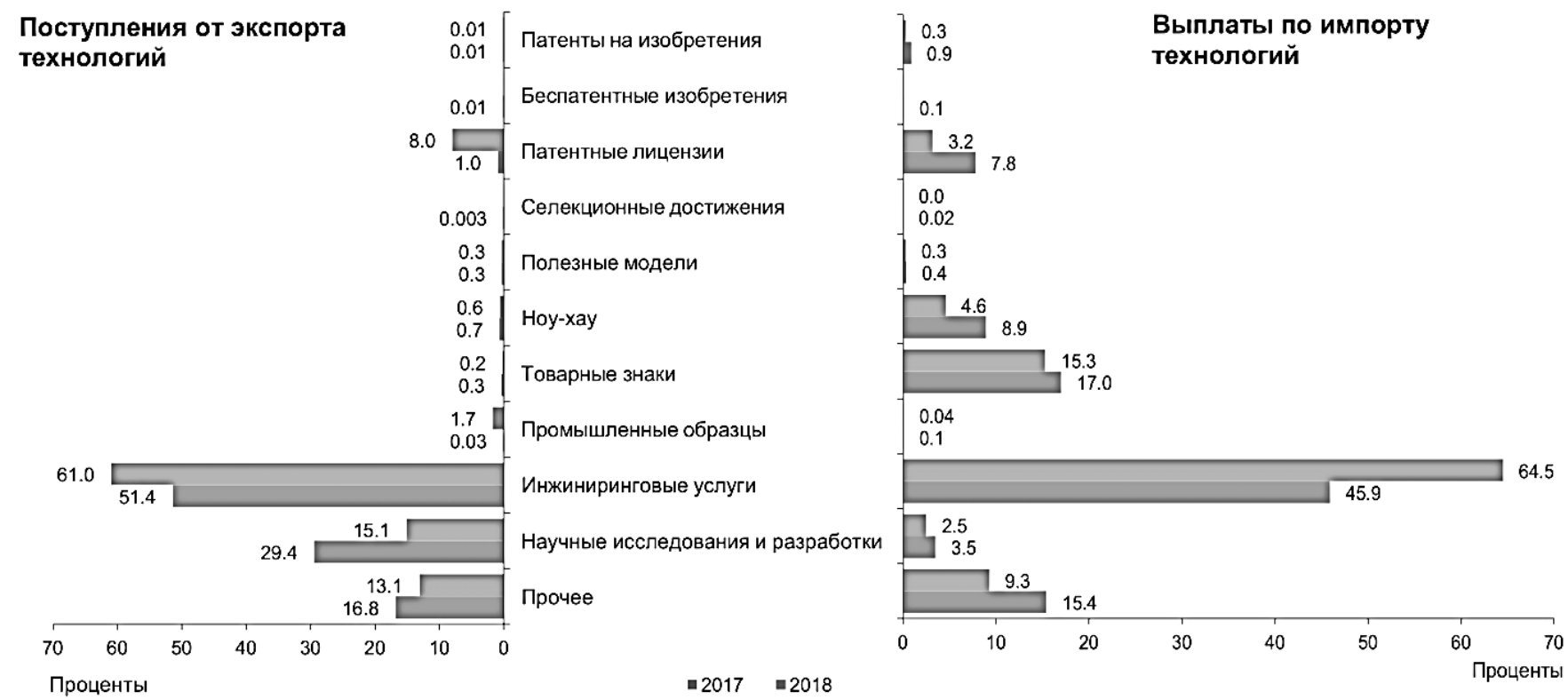

Рис. 2. Структура экспорта и импорта технологий России по категориям соглашений (в \%) [3]

полезные модели и патентным лицензиям довольно мала - всего лишь 1,3\% по экспорту и 9,1\% по импорту.

Такое соотношение данных говорит о превалирующей доле неохраноспособных объектов в международном обмене технологиями. И лишь по категории соглашений, являющиеся результатами НИОКР, заметно положительное сальдо в размере 300 миллионов долларов США.
Почти до 2012 года включительно, российские технологии преимущественно экспортировались в развивающиеся страны. В течение данного периода доля стран ОЭСР в структуре технологического экспорта России варьировалась в пределах 40\%. С 2013 года значение выросло до 71\%, но потом в 2015 сократилось почти вдвое и достигло отметки в 37,5\%. Тем не менее, рост возобновился, и в 2018 году доля стран ОЭСР в структуре экспорта добралась до 58,9\% (см. рис. 3). 
Поступления от экспорта технологий

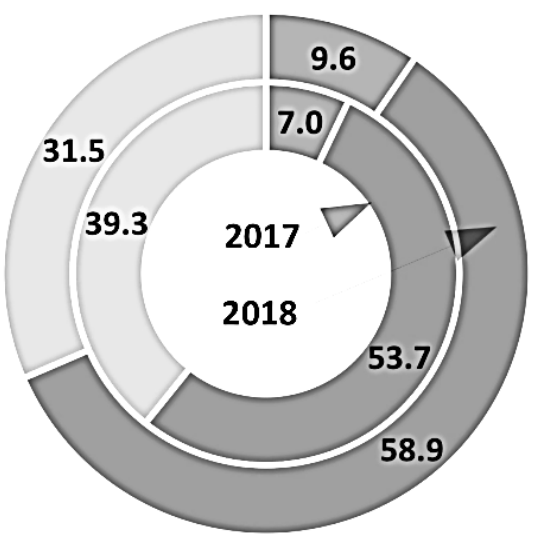

\section{Выплаты по импорту технологий}

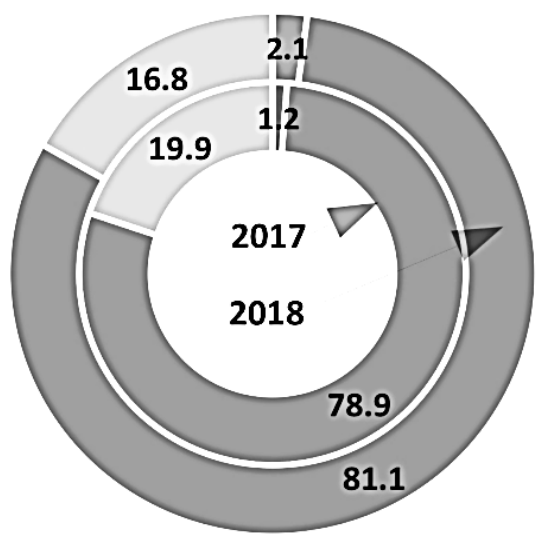

\section{- Страны СНГ п Страны ОЭСР Другие страны}

Рис. 3. Структура экспорта и импорта технологий России по группам стран (в \%)[3]

Что же касается импорта, то и в нем преимущественная доля остается за странами ОЭСР: $81,1 \%$ от общего размера выплат по импорту технологий приходятся на эти государства.

Больше всего денежных поступлений от технологического экспорта в 2018 году из стран ОЭСР приходятся на такие страны, как США, ФРГ и Швейцарию - 224,3 миллионов долларов США, 141,9 и 91 соответственно, из стран СНГ - на Беларусь (68,5 миллионов долларов) и Казахстан (23,7 миллионов долларов), из стран Азии на Китай и Индию (90,8 и 52,3 миллионов долларов соответственно) [3].

Основная же часть выплат по импорту в 2018 году была направлена в ФРГ (505,4 миллиона долларов США), США $(420,1)$, Швейцарию $(242,6)$, Нидерланды $(177,2)$, Великобританию $(173,8)$, KHP $(165,3)$, Францию $(145,3)$ и Италию $(115,5)[3]$.

Таким образом, на международном рынке технологий Россия занимает невысокую позицию. Несмотря на то, что в рейтинге R\&D World страна занимает 8 место по размерам вложений в НИОКР, внешнеторговое сальдо по-прежнему велико, хотя за период с 2017 по 2018 год наметилась тенденция к его снижению.

Масштабы России на рынке по-прежнему малы, и в рейтинге ОЭСР за 2015 год государство заняло всего лишь 27 строчку по количеству трансакций.

В рейтинге из 129 стран мира по глобальному инновационному индексу, составленном французской бизнес-школой INSEAD, BOИС и университетом Корнелл,
Российская Федерация сохраняет 46-ю позицию в ГИИ в 2019 году [5].

РФ улучшила две позиции в субиндексе инновационных ресурсов (41-е место) и заняла 59-е место в субиндексе инновационных результатов, потеряв три позиции с прошлого года. Что касается входных данных, то она повышает свою позицию по показателям инфраструктуры (62-е место, рост на 1), и имеет более высокий рейтинг в области информационных и коммуникационных технологий (29-е место, рост на 8), а также в показателях использования ИКТ (45-е место), онлайн-услуг правительства (25-е место) и электронном участии (23-е). Несмотря на потерю одной позиции в области человеческого капитала и научных исследований (23-е место), в этом году Российская Федерация демонстрирует сильные стороны в сфере высшего образования (14-е место) из-за высокого уровня приема в ВУзы (17-е место) и выпускников в области науки и техники (10-е место). По импорту высокотехнологичных товаров РФ занимает 39-е место. Что касается результатов инновационной деятельности, то она сохраняет свои позиции как в субпостах «Знания и технологии» (47-е место), так и в «Творческих результатах» (72-е место). Потеряв две позиции в области создания знаний, Россия сохраняет максимальные результаты в патентах по происхождению (20-е место), а также в полезных моделях (8-е место). По качеству инноваций она сохраняет 3-е место среди стран со средним уровнем дохода [5].

Такая слабая позиция России на международном рынке технологий обусловлена целым рядом проблем. Для их решения 1 декабря 2016 года президент Российской Федерации В.В. Путин издал указ «О Стратегии 
научно-технологического развития Российской Федерации», где четко изложены цели и основные задачи НТР России, обозначен ряд проблем, определены принципы, приоритеты, основные направления и меры реализации государственной политики в этой области, а также ожидаемые результаты реализации настоящей Стратегии, обеспечивающие устойчивое, динамичное и сбалансированное развитие страны на долгосрочный период.

В первую очередь, в указе отмечается, что для осуществления данной Стратегии по решению проблем в области НТР России необходима консолидация усилий разных организаций: органов государственной власти как на федеральном, так и на уровне субъектов РФ, различных научно-образовательных, исследовательских и предпринимательских сообществ, а также организаций, осуществляющие научную, научно-техническую и инновационную деятельность, институтов гражданского общества по созданию благоприятных условий для применения достижений науки и технологий в интересах социально-экономического развития государства.

Исторически сложилось, что Россия признана одной из мировых научных держав. Отечественные научные и инженерные школы эффективно справлялись с задачами роста и развития сфер социальной и экономической жизнедеятельности человека, а также обеспечивали достойный уровень внутренней безопасности страны. Был внесен ценный вклад в накопление научно-технических знаний и изобретение передовых технологий и инноваций. Согласно Стратегии, этому посодействовала грамотно проработанная система организации исследований и разработок. Например, концентрация ученых и инженеров в высшей школе во времена императорской России благоприятствовала созданию и накоплению новых знаний. Академия наук СССР, а также отраслевые институты согласно плану Государственного комитета Совета Министров СССР по науке и технике и Госплана СССР проводили крупные научно - исследовательские разработки за счет сосредоточения финансовых и интеллектуальных ресурсов в данном учреждении.

После распада СССР и образования в 1991 году Российской Федерации государство столкнулось с необходимостью определения и выделения нового места для науки в обществе в связи с рыночным вектором развития экономики страны. Так, государственная научно-техническая политика после распада СССР подразделяется на два основных и значимых этапа: с 1991 по 2001 годы и с начала 2000-х годов по настоящее время.

Первый этап характеризуется адаптацией к рыночной экономике и оптимизацией к кризису. Целью этого этапа было сохранение имеющегося потенциала страны в научно-технологической области, разработка новых механизмов поддержки НТР, а также должное финансирование ведущих организаций данной области и создание благоприятных условий для международной кооперации.

Второй этап непосредственно определяется увеличением размеров финансирования науки и последующим переходом государства к инновационной экономике.

К сожалению, несмотря на важную роль России в мировой науке и наличие некоторых действительно конкурентоспособных и уникальных технологических разработок ее технологическое развитие сильно отстает от мирового темпа, заданного лидерами международного рынка технологий. Причиной такой невысокой и слабой позиций Российской Федерации на рынке является целый ряд проблем, которые препятствуют научно-технологическому развитию.

1. У России хороший потенциал в области фундаментальных научных разработок и исследований, причем как на национальном, так и на международном уровне, но их актуальность соответствует научным направлениям последних десятилетий прошлого века.

2. Существует большое количество научно-образовательных центров, но они сильно дифференцируются по эффективности и результативности своей работы, и лишь в некоторых субъектах России концентрируется научно-исследовательский потенциал.

3. Школьники и студенты принимают активное участие и часто побеждают в международных научно-технических мероприятиях, конкурсах, олимпиадах и т.д., но в последствие наблюдается отсутствие стремления реализовать себя в этих областях. Несмотря на рост числа научных работников в возрасте до 39 лет, в стране до сих пор существует проблема «утечки умов», поскольку взаимодействие сектора НИОКР с реальным экономическим сектором остается на низком уровне, хотя по размерам инвестиций в НИОКР Россия занимает 8 место в рейтинге. В результате Россия выступает в качестве донора человеческого капитала для мировой науки.

4. Общество и экономика по-прежнему слабо восприимчива к инновациям, что тормозит практическое применение результатов НИОКР. Также плохо развит технологический обмен оборонного и гражданского секторов экономики, что тоже препятствует развитию технологий двойного назначения.

5. Несмотря на объемы инвестиций в НИОКР и рост числа научных сотрудников, эффективность и результативность исследовательских центров России значительно малы, и уступают 
странам-лидерам международного рынка технологий: небольшое количество публикаций в высокорейтинговых журналах, выданных международных патентов, доходов от технологического экспорта. По результативности Россия расположилась на ряду со странами Восточной Европы и Латинской Америки.

6. В то же время сохраняется несогласованность приоритетов и инструментов НТР в России на всех уровнях. Это затрудняет формирование добавленной стоимости на созданные технологические продукты и услуги и получение от них наибольшего мультипликативного эффекта.

Помимо проблем, указанных выше, существует и ряд других, более серьезных, которые в Стратегии именуются как «большие вызовы». Это совокупность масштабных проблем и угроз, которые не решаются путем увеличения ресурсов и которые требуют объективной реакции государства. «Большие вызовы» создают риски отставания России от мирового темпа НТР, но в то же время способствуют появлению новых возможностей и перспектив в российском научно-технологическом развитии.

Наиболее значимыми вызовами являются следующие проблемы.

1. Исчерпание возможностей экономического роста страны в связи с большой сырьевой зависимостью, а также отставание от стран-лидеров, где активно формируется цифровая экономика, используются передовые технологии и возобновляемые ресурсы.

2. Новые социальные и медицинские проблемы, возникающие на фоне роста продолжительности жизни населения, изменения образа жизни людей, появления новых штаммов и возвращению исчезнувших инфекций, а также повышения риска пандемий.

3. Проблема воспроизводства природных ресурсов в связи с масштабным ростом антропогенной нагрузки на окружающую среду.

Таким образом, наиболее значимыми вызовами являются сырьевая зависимость, социально-медицинские проблемы и воспроизводство природных ресурсов.

Опираясь на глобальные изменения в организации научно-технической и инновационной деятельности, Россия определила для себя ряд внутренних факторов, которые в перспективе могут поспособствовать улучшению позиции страны на международном рынке технологий:

- сжатие инновационного цикла (т.е. сокращение времени между приемом новых знаний, разработок и непосредственно воплощением в жизнь технологических товаров и услуг, а также их поступлением на рынок),

- размытие в исследованиях и разработках дисциплинарных и отраслевых границ,

- многократное увеличение доли научно-технологической информации и изменение способов работы с ней,

- повышение требований к квалификации научных работников,

- большее осознание важности международных стандартов.

Помимо внутренних факторов необходимо определить и приоритеты технологического развития России с учетом глобальных тенденций. Так, в ближайшие 1015 лет государство должно провести преобразования, наиболее важными из которых являются следующие.

1. Перейти к передовым цифровым технологиям, автоматизации процессов и роботизации систем, изобретению и использованию ряда новых материалов и т.д.

2. Перейти к использованию к экологически чистой и ресурсосберегающей энергии, а также к формированию ее новых источников.

3. Перейти к высокотехнологичному здравоохранению.

4. Создать такие интеллектуальные транспортные и телекоммуникационные системы, которые смогут обеспечить связанность территорий Российской Федерации, а также сохранение лидерских позиций в международной транспортно-логистической системе, в освоении Арктики и Антарктики, Мирового океана и космоса.

Необходимо сделать акцент на том, что к тому времени российское общество должно научиться прогнозировать рождающиеся большие вызовы и пресекать их на корню. Вдобавок обеспечить должную поддержку фундаментальной науке, как основополагающей долгосрочного развития всей нации.

Особая роль в реализации проставленных задач отводится Министерству науки и высшего образования РФ - и целому ряду участников программы: министерства, федеральные службы и агентства, ВУЗы. Именно они будут способствовать реализации данного Постановления, в частности осуществлению пяти подпрограмм. Также документ содержит цели и задачи, размеры ежегодных вложений на реализацию данной программы с 2019 до 2030 года и ожидаемые результаты, которые вполне реализуемы, но некоторые вызывают сомнения.

Стоит заметить, что в Стратегии приведены два сценария развития науки и техники России [4]: импорт тех- 
нологий и фрагментарное развитие или занятие лидерских позиций по избранным направлениям НТР в рамках традиционных и новых технологических товаров и услуг. Но предпочтение отдается именно второму варианту развития, поскольку только он поможет преодолеть сложившиеся проблемы и достичь России показателей стран-лидеров международного рынка технологий.

Второй сценарий предполагает перестройку сектора исследований, разработок и инноваций как на корпоративном, так и на государственном уровне, а также опережающее увеличение расходов на НИОКР. Данный вариант развития потребует перераспределение ресурсов и их концентрацию на получение новых научно-технологических результатов, реализацию нового комплекса организационных, правовых и других мер для повы- шения эффективности и отдачи от вложенных средств, а также партнерство и сотрудничество с зарубежными исследовательскими организациями и центрами, а также совместное учреждение компаний, которые смогут занять лидирующие позиции на новых глобальных рынках технологий.

Таким образом, несмотря на отсутствие больших перспектив для России на международном рынке технологий в ближайшее время, государство намерено бороться с рядом проблем, которые препятствуют этому, а также нацелено на концентрацию своих сил на избранных направлениях научно-технологического развития и достижение на них лидерских позиций, поскольку такие направления, где Россия активно преуспевает, уже существуют.

\section{ЛИТЕРАТУРА}

1. Глобальные тренды и перспективы научно-технологического развития Российской Федерации: краткие тезисы: доклады к XVIII Апр. междунар. науч. конф. по проблемам развития экономики и общества, Москва, 11-14 апр. 2017 г. / Л. М. Гохберг, А. В. Соколов, А. А. Чулок и др.; Нац. исслед. ун-т «Высшая школа экономики».— М.: Изд. дом Высшей школы экономики, 2017. [Электронный ресурс].— URL: https://www.hse.ru/data/2017/04/21/1168819587/ Gohberg_2017.pdf (дата обращения: 17.11.2019)

2. Постановление Правительства Российской Федерации от 29.03.2019 г. № 377 «0б утверждении государственной программы Российской Федерации «Научно-технологическое развитие Российской Федерации». [Электронный ресурс].—URL: http://static.government.ru/media/files/AAVpU2sDAvMQklHV20ZJZc 3MDqcTxt8x.pdf (дата обращения: 16.11.2019)

3. Сагиева Г.С., Коцемир М. Н. Внешняя торговля технологиями России. / ИСИЭЗ НИУ ВШЭ.— 2019._ URL: https://issek.hse.ru/data/2019/08/01/1484726209/ NTI_N_138_01082019.pdf

4. Указ Президента Российской Федерации от 01.12.2016 г. № 642 «0 Стратегии научно-технологического развития Российской Федерации». [Электронный pecypc].—URL: http://kremlin.ru/acts/bank/41449

5. The Global Innovation Index 2019. Cornell University, INSEAD, WIPO. [Электронный ресурc].— URL: https://www.wipo.int/edocs/pubdocs/en/wipo_pub_ gii_2019.pdf

( ) Асон Татьяна Анатольевна ( tatiana_ason@mail.ru ), Муталлапова Альбина Артуровна ( albinka0299@yandex.ru ).

Журнал «Современная наука: актуальные проблемы теории и практики» 